\title{
HISTORICAL ANALYSIS OF STUDENTS' PERFORMANCE: AN AGE AND GENDER PERSPECTIVE
}

\author{
Silvia B. González-Brambila, Lourdes Sánchez-Guerrero, Beatriz A. González-Beltrán, \\ \& Josué Figueroa-González \\ Systems’ Department, Universidad Autónoma Metropolitana (Mexico)
}

\begin{abstract}
It is possible that innate characteristics can have a certain effect on the students' performance. Two of the most important characteristics of a person are their gender and their age. Universities are institutions that must be opened for every person, not mattering their age of gender, however it could be possible that these factors could represent a decisive factor over students' performance. For this reason, educational analytics must be performed for determining if there is a relationship between the age, the gender and both of them over students' performance. The goal of this work is to show if there is a relationship between age and gender over the performance of engineering students. Results show that gender is not a decisive factor for determining if a student will finish their studies, but age clearly represents a topic to be considered.
\end{abstract}

Keywords: Students' performance, measurements in education, educational analytics, age and gender influence.

\section{Introduction}

Several factors that can affect the performance of students during their studies, labor, personal or familiar ones that can occur during the time students course a superior level of education. However, it is also clear that innate characteristics can have a specific effect on the students' performance. Two of the most important characteristics of a person are their gender and their age. Universities are institutions that must be opened for every person, not mattering their age of gender; however, it could be possible that these factors could represent a decisive factor over students' performance.

In the Mexican university Universidad Autonoma Metropolitana Azcapotzalco (UAM), students of Engineering programs invest twice the time originally established, and a high percentage of students do not finish their studies. For this reason, several studies are being performed for finding the factors that can have a higher impact on the fact that a student finish or not her/his studies.

Nowadays, there is much information that educational institutions store; however, a huge amount of data make difficult the analysis, thousands of registers from students stored in a textual way are almost impossible to analyze for finding patterns of interest, however, applying concepts like Information Visualization as mentioned in Herman (2000) or learning analytics, Siemens (2011), allows presenting data in a way that it is easier understandable for humans.

There are several studies considering eventual gender differences, most of them suggest that women have higher achievements in Higher Education. For example, Vasconcelos \& Leandro (2018) observed that in Portugal at the end of the first semester, women present a higher rate of successful curricular units than men in engineering courses. They describe that women dedicate more time studying, obtain higher average grades, show greater time and activities organization, and are self-regulated learners.

It's true that more women are in school today than ever before but not always have the same opportunities as men. According to the UNESCO report by Chavatzia (2017), women are under-represented in science, technology, engineering and mathematics (STEM) education, with only $35 \%$ in higher education globally. For example, only $3 \%$ of female students in higher education choose information and communication technologies studies, and this is relevant because STEM carries are often referred to as the jobs of the future. 


\section{The goal of the research}

It is essential to consider identifying factors or characteristics that could have a special relationship with the fact that a student could or not finish their studies. Both of the most important features of students are their gender and their entrance age, this is, how old they were when they were accepted into UAM. For this reason, educational analytics must be performed for determining if there is a relationship between age, gender and both of them over students' performance. This performance is measured considering if students finished their studies or not, and if they finish them, how many times do they need it. The goal of this work is to show in a clear way if there is a relationship between ages and gender in the fact that student's finish or not their studies.

\section{Data analysis}

Statistical analysis was considered for this work, also using different visualization techniques were applied; these two knowledge areas nowadays are being very used in education analysis for finding interesting patterns.

For this study were analyzed 3055 students from the ten Engineering programs of UAM considering the last 12 years. Were performed different analysis: grouping students into different age sets (considering the entrance age), grouping students according to their gender, and finally, combining age and gender.

Results were presented using different Information Visualization techniques according to the desired information to show. Some traditional graphs like bar plot graphics were used; however, for showing the distribution in certain groups of values, it was considered the boxplot graphic, a very useful tool for showing distribution's analysis, Williamson (1989). The statistical analysis has shown:

- Percentage of male students that have finished or did not finish their studies.

- Percentage of female students that have finished or did not finish their studies.

- From those who finished, the distribution of years that the needed for finishing, this for male and female students.

- Distribution of entrance ages of those students that finished or not their studies.

- Distribution of entrance ages for those male and female students that finished their studies.

- Distribution of entrance ages for those male and female students that did not finish their studies.

The number of analyzed students which enrollment UAM from 2008 to 2016 was 3055, this considering only those who had or had not finished their studies, students that are studying were discarded. Figure 1 shows the overall percentage of engineering students at UAM.

Figure 1. Overall percentage of engineering students considering gender that enter, finish or not in UAM.

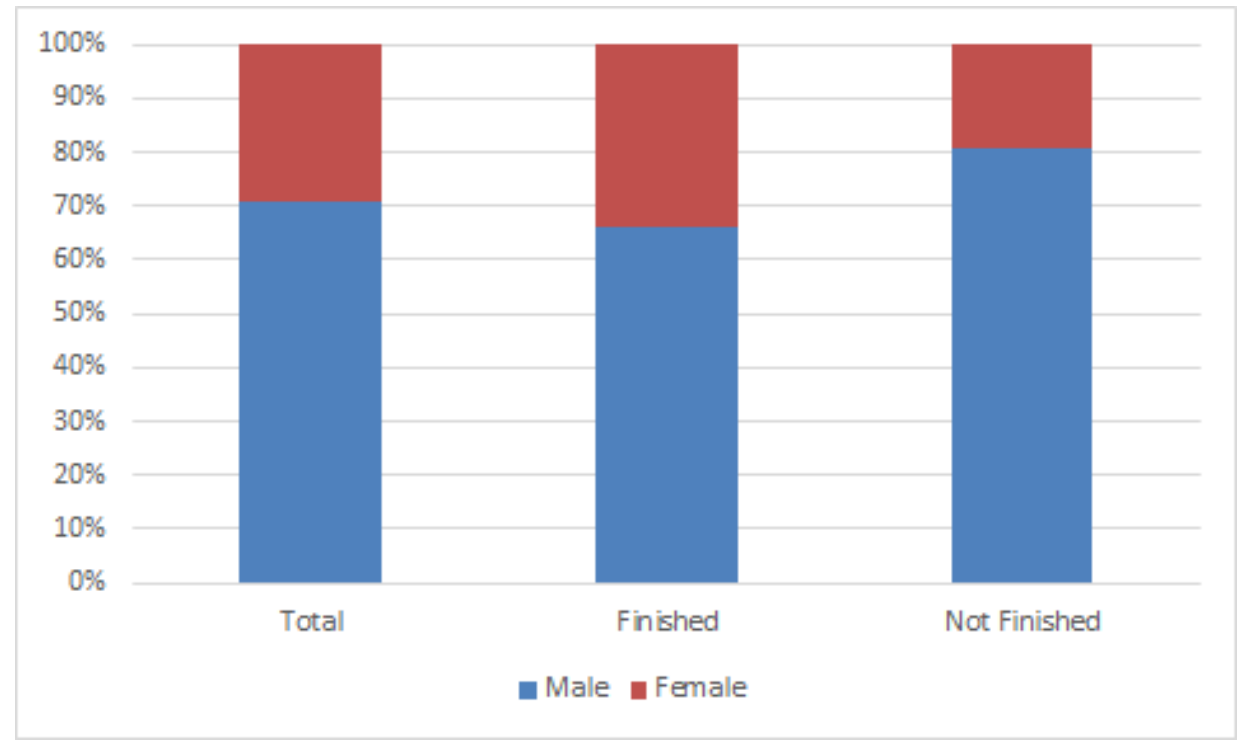

Distribution of needed time for finishing their studies for those students that finished their studies considering their gender is shown in Figure 2. 
Figure 2. Distribution of years needed for finishing studies according students' gender.

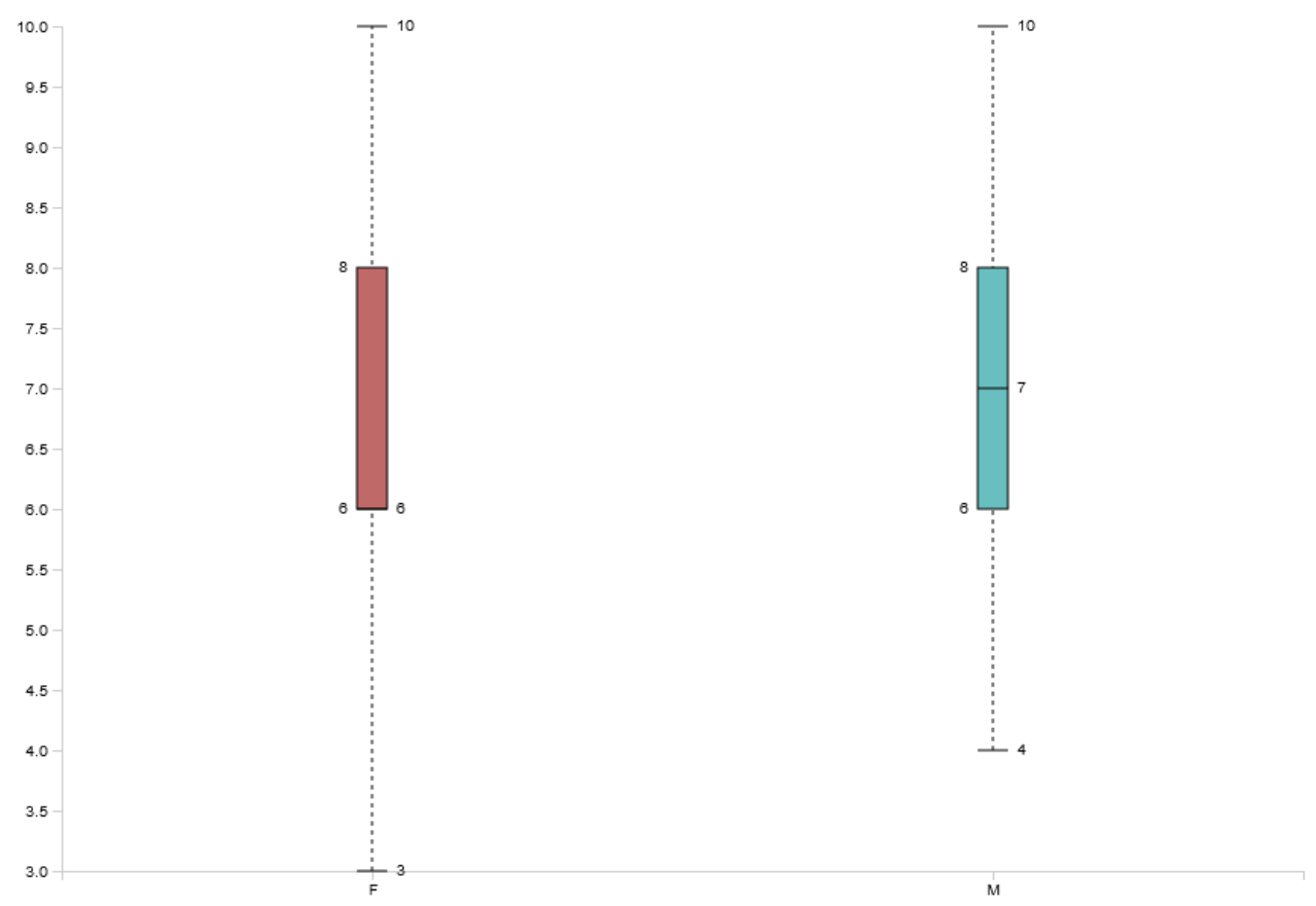

Figure 3 shows how does the entrance age is distributed for those students that finished or not their studies.

Figure 3. Distribution of entrance age of students according if they finished or not.

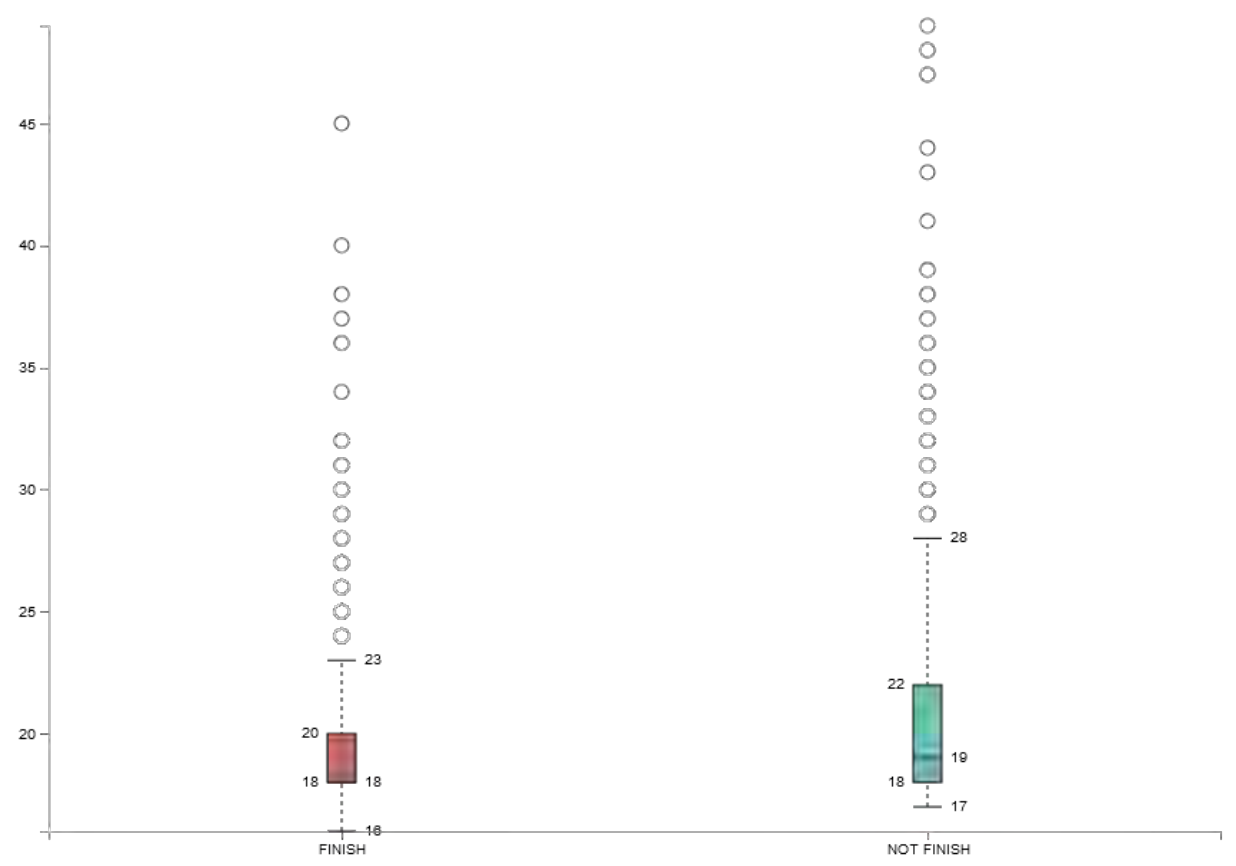

For male students, the distribution of entrance ages according to if they finished or not their studies is presented in Figure 4. 
Figure 4. Distribution of entrance age for male students.

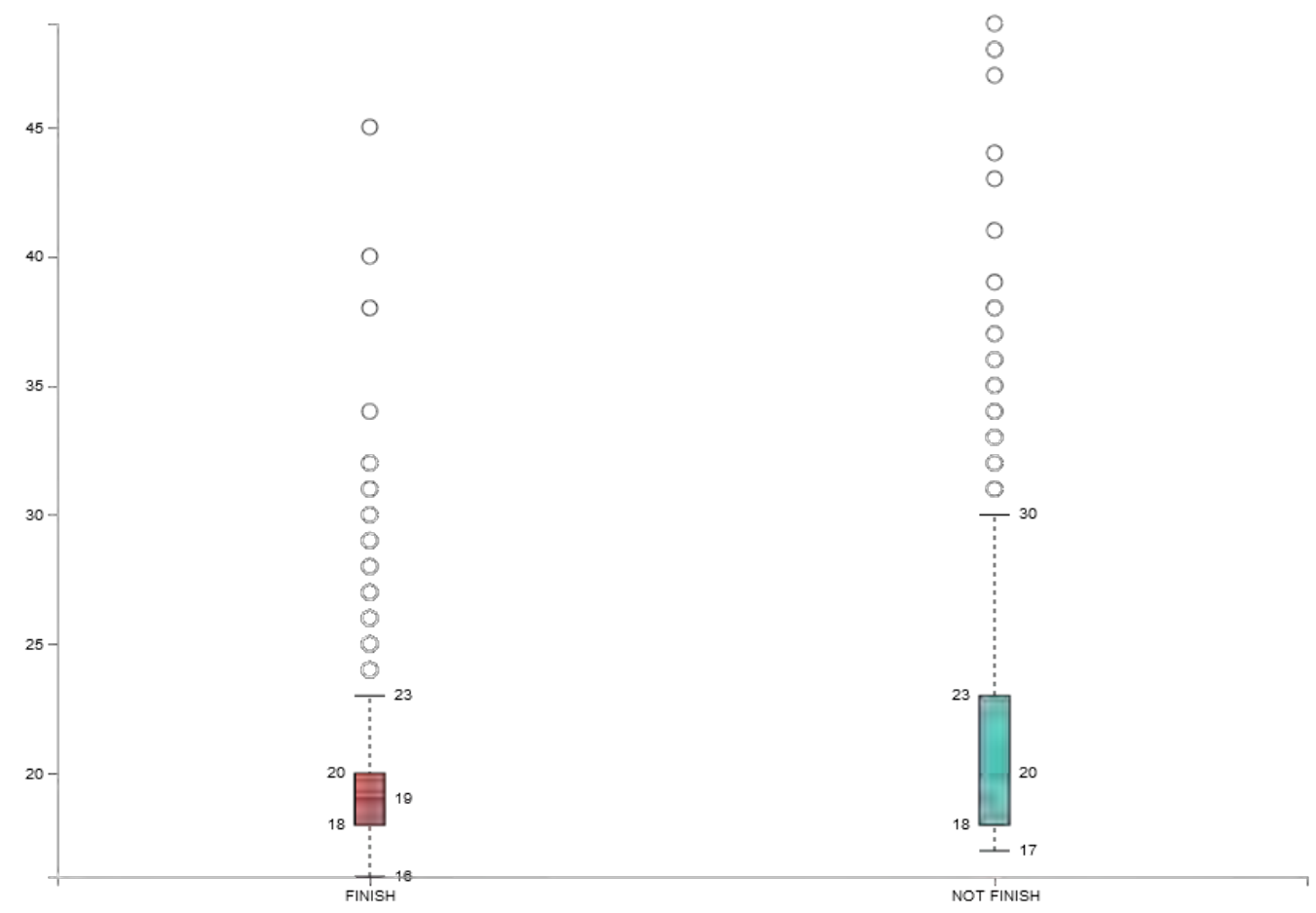

Finally, the distribution of entrance ages for female students according to if they finished or not their studies is presented in Figure 5.

Figure 5. Distribution of entrance age for female students

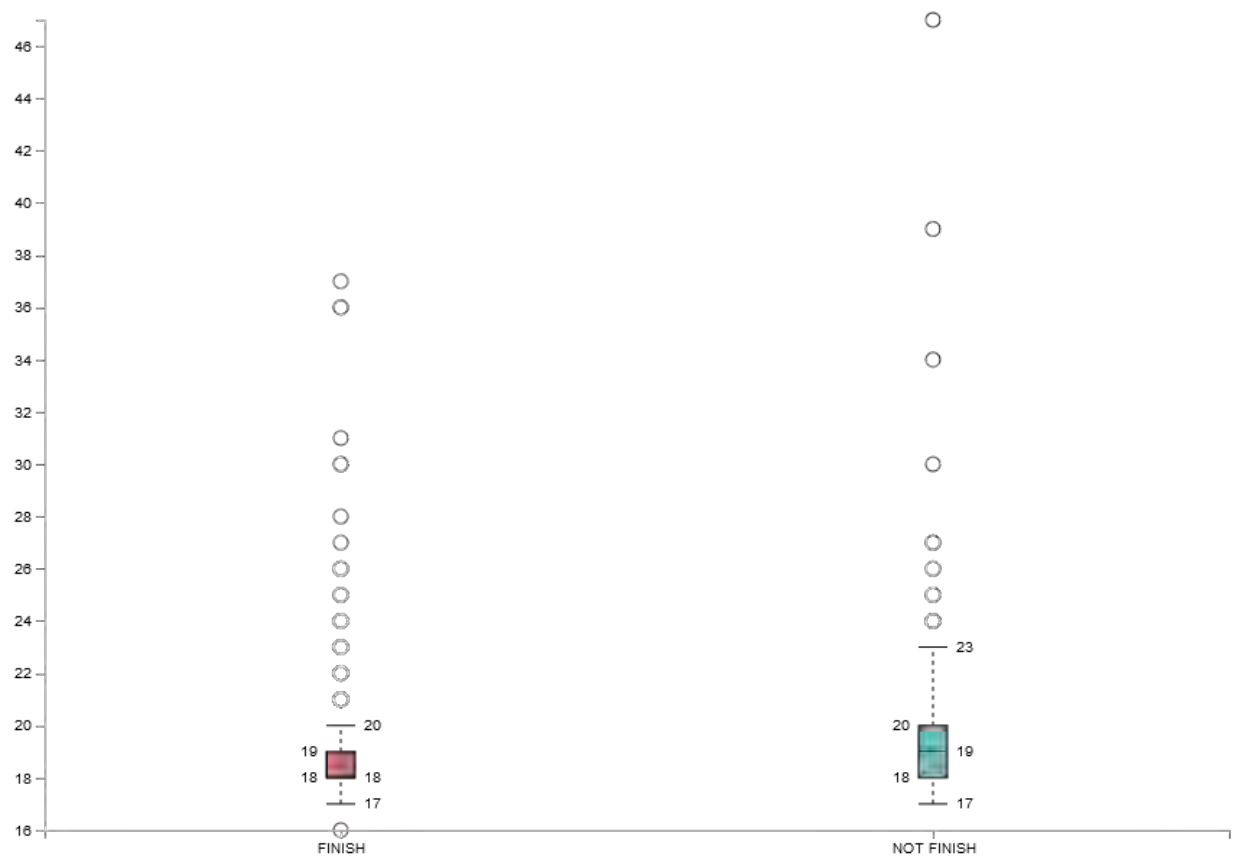

\section{Analysis}

After generating the different graphs, they were analyzed, the results are presented next: Figure 1 shows that the total number of male engineering students is considerably larger than female students. The percentage of female students that finish their studies is more significant than the one of male students, approximately 18\% bigger. This is also shown in Figure 1, where male students have a little more than $60 \%$ of success, and female students has nearly $80 \%$. 
Figure 2 shows the distribution of needed time for finishing their studies according the student's gender, and it is clear that the behavior is very similar, $50 \%$ of both genders required from 6 to 8 years and $25 \%$ needed from 8 to 10 years. Again, female students have better behavior because $25 \%$ of them required from 3 to 6 years for finishing, meanwhile $25 \%$ of male students needed from 4 to 6 years, one year of difference.

Figure 3 shows that $25 \%$ of students are between 16 and 18 years old, $50 \%$ of students that finished their studies are between 18 and 20 years old, and $25 \%$ between 20 and 23 . Students aged more than 23 years that ended their studies are considered atypical values. For those students who did not finish their studies, $25 \%$ is between 17 and 18 years old, 50\% between 18 and 22 and $25 \%$ between 22 and 28 years old. This means that at an older age, is most common that students did not finish. Ages older than 28 years that did not finish are considered non typical.

The same information, but only for male students, presented in Figure 4, shows a similar behavior, however, the limit of ages for being considered atypical for not finishing higher studies raises two years, passing from 28 to 30. This means that are more male students which entered older to UAM, but, commonly, they did not finish their studies.

Finally, distribution of ages for female students, presented in Figure 5, shows that the limit for being considered atypical for finishing their studies is 20 years, three years younger than male. Meanwhile, the older for being considered not atypical for not finishing is 23 years old, seven years younger than the male one. Male and female students have a similar behavior for those that finished their studies.

\section{Conclusions}

Student gender has not a significant impact on the fact that students finished or not their studies. Female students have a little better performance considering the percentage of students that completed engineering programs and the distribution of years needed for finishing, but it is not very clear. The rest of the behaviors are very similar to both genders.

From the entrance age, it is clear that those students who enroll UAM in ages from 18 to 20 have more opportunities for finishing their studies. Students who are older than 23 years old and complete their studies are considered atypical values, meaning that if they finish, this not necessarily represent that this range of age could complete their studies. However, students that enter older than those 23 years old (or even, 22 years old) and to 30 still have a significant relevance in the group of students that did not finish their studies, meaning that the fact that they do not complete their studies still is not due to coincidence or an atypical case.

The topic of entrance age is interesting: older age students could have other responsibilities, as their own family or a job that did not allow them to focus on their studies as younger students could. However, any higher education institution could not select students according to their entrance age, it is a discriminatory issue. On the other hand, accepting students older than some age could represent that they could not finish their studies, generating problems for the universities whose percentage of successful students will be affected.

It is an excellent opportunity to bring individual support for those students who are in high-risk groups of not complete the engineering programs. To diminish high dropout rates in engineering programs are a semi-face-to-face program to go to UAM only one day a week. This program just started a quarter ago, and it is still too soon to have results.

\section{References}

Chavatzia, T. (2017). Cracking the code: Girls' and women's education in science, technology, engineering and mathematics (STEM) (Vol. 253479). Paris: UNESCO Retrieved from http://unesdoc. unesco. org/images/0025/002534.

Herman, I., Melançon, G., \& Marshall, M. S. (2000). Graph visualization and navigation in information visualization: A survey. IEEE Transactions on visualization and computer graphics, 6(1), 24-43.

Siemens, G., \& Long, P. (2011). Penetrating the fog: Analytics in learning and education. EDUCAUSE review, 46(5), 30 .

Vasconcelos, R. M., \& Almeida, L. S. (2018). Learning and academic success in engineering courses: Comparing 1st year students according to gender. IEEE Frontiers in Education Conference (FIE), 1-4.

Williamson, D. F., Parker, R. A., \& Kendrick, J. S. (1989). The box plot: a simple visual method to interpret data. Annals of internal medicine, 110(11), 916-921. 